Review Article

\title{
Current Data on Risk Factor Estimates Does Not Explain the Difference in Rates of Melanoma between Hispanics and Non-Hispanic Whites
}

\author{
Sonia Kamath, ${ }^{1}$ Kimberly A. Miller, ${ }^{2}$ and Myles G. Cockburn ${ }^{1,2}$ \\ ${ }^{1}$ Department of Dermatology, Keck School of Medicine of the University of Southern California (USC), 1200 N State Street, \\ Room 3250, Los Angeles, CA 90033, USA \\ ${ }^{2}$ Department of Preventive Medicine, Keck School of Medicine of USC, 2001 N. Soto Street, Suite 318-A, Los Angeles, CA 90032, USA \\ Correspondence should be addressed to Sonia Kamath; shkamath@med.usc.edu
}

Received 15 November 2015; Revised 23 February 2016; Accepted 23 February 2016

Academic Editor: Günther Hofbauer

Copyright (C) 2016 Sonia Kamath et al. This is an open access article distributed under the Creative Commons Attribution License, which permits unrestricted use, distribution, and reproduction in any medium, provided the original work is properly cited.

\begin{abstract}
United States Hispanics have seven times lower melanoma incidence rates than non-Hispanic whites (NHW). It is unclear whether this difference can be explained solely by phenotypic risk factors, like darker skin, or whether modifiable risk factors, like sun exposure, also play a role. The purpose of this paper is to summarize what is currently known about melanoma risk factors among Hispanics and NHWs, and whether or not those differences could explain the difference in melanoma incidence. Through literature review, relative risks and prevalence of melanoma risk factors in Hispanics and NHWs were identified and used to calculate the expected rate in Hispanics and rate ratio compared to NHWs. We found that melanoma risk factors either have similar frequency in Hispanics and NHWs (e.g., many large nevi) or are less frequent in Hispanics but do not explain a high proportion of disease variation (e.g., red hair). Considering current knowledge of risk factor prevalence, we found that melanoma incidence rates in the two groups should actually be similar. Sun exposure behavior among Hispanics may contribute to the explanation for the 7fold difference in melanoma rates. Currently, limited data exist on sun exposure behavior among Hispanics, but possibilities for improving primary prevention by further studying these practices are substantial.
\end{abstract}

\section{Introduction}

Hispanics are the largest ethnic group in the United States, and over the last few decades, rates of melanoma among Hispanics have steadily risen $[1,2]$. In California, where Hispanics comprise almost $40 \%$ of the population, increases in melanoma have occurred for tumors with the worst prognosis [3-5]. Hispanics are diagnosed with melanoma at later stages than non-Hispanic whites (NHW), leading to increased likelihood of metastasis and higher mortality $[3,6,7]$. Still, the rates of melanoma in the Hispanic population remain approximately seven times lower than in the NHW population in California [3]. This difference in melanoma incidence between Hispanics and NHWs has traditionally been attributed to the protective effects of darker skin pigmentation [5]. However, Hispanics have significant heterogeneity of skin color and phototype (including light skin color), and it is well known that ultraviolet (UV) exposure plays a role in the development of melanoma regardless of skin type $[8,9]$. In fact, it is unclear whether key melanoma risk factors, including increased numbers of nevi, freckling, poor tanning ability, and fair complexion, differ substantially between Hispanics and NHWs $[10,11]$. Few studies describe melanoma risk factors in Hispanics, or those risks relative to NHWs [12]. Most studies have focused on determining relative risks (RRs) for melanoma in NHWs, and few estimate melanoma burden attributable to each risk factor $[13,14]$.

In this review, we examined what is currently known about the risk factors for melanoma and their distribution among Hispanics and then calculated expected rate ratios (NHW compared to Hispanic) for each risk factor based on published estimates of relative risk and risk factor prevalence in the two groups. We found that, based on what is currently known about the risk factors, the rates of melanoma among 
Hispanics and NHWs should be quite similar, and the fact that they are not similar may present an opportunity to investigate modifiable risk factors for melanoma-for which very little data exists in the Hispanic population-and to improve prevention efforts.

\section{Materials and Methods}

2.1. Defining the Risk Factors for Melanoma. For summary relative risk (RR) measures for melanoma risk factors, we used a comprehensive meta-analysis by Gandini et al. of 83 observational studies through September 2002 [20-22]. A PubMed search covering observational studies through April 2013 was conducted to provide a RR range for those risk factors not included in the meta-analysis.

Phenotypic risk factors for melanoma in the meta-analysis include blonde or red hair, many freckles, nevus counts, and Fitzpatrick phototype I or II. For freckles, the RR presented in the meta-analysis compared estimates for high versus low density of freckles. We focus on risk associated with increased numbers of common nevi, since dysplastic nevi have been noted to occur specifically in melanoma-prone families $[22,23]$. Sunburn and sun exposure represent important risk factors for melanoma. Sun exposure was divided into total lifetime, intermittent, and chronic exposure. Intermittent sun exposure included estimates based on recreational activities, while chronic sun exposure was assessed as occupational exposure. Where multiple levels of exposure were reported, the highest level was included $[20,21]$.

For counts of large nevi, history of one or more childhood sunburns, and history of one or more lifetime sunburns, RRs were not summarized in the meta-analysis, so a literature search was conducted. Combinations of the following keywords and $\mathrm{MeSH}$ terms were used in PubMed: melanoma, etiology, epidemiology, prevention and control, risk factors, case-control studies, cohort studies, cross-sectional studies, nevus, skin pigmentation, skin color, hair color, sun exposure, sunlight, ultraviolet rays, sunburn, suntan, and sunbathing. Included studies were limited to those in English and those examining adult populations. Duplicates, reviews, and irrelevant articles were excluded. Other studies were excluded for ineligible study design (e.g., case series) (14 studies); using outcome of second primary melanoma (11 studies); not being independent of other included studies (3 studies); presenting data by gender, body site, or melanoma subtype (16 studies); or focusing on a restricted age group (1 study). An exception was made for Qureshi et al. and Han et al., as although they are based on the same cohort, the risk factors examined in each are different $[24,25]$.

We extracted study location, study design, number and source of cases and controls, age of study population, definitions and categories of risk factors, prevalence estimates, RR or odds ratio (OR) estimates, 95\% confidence interval (CI), and variables for which statistical adjustment was done. For articles that presented multiple estimates, we recorded the one adjusted for the most confounders. For risk factors not included in the Gandini meta-analysis, the RR range represents estimates from all included studies, and the median of this range is reported in place of a summary statistic. For other risk factors, the RR range is provided as an update of studies published after 2002 .

2.2. Calculating the Expected Rate Ratio of Melanoma in NonHispanic Whites Compared to Hispanics. In order to compare the melanoma rates between Hispanics and NHWs in California, we obtained California population-based risk factor prevalence data wherever possible. The California Health Interview Survey (CHIS) provides information on sunburn prevalence in NHWs and Hispanics [18]. We obtained the prevalence of having more than three lifetime episodes of sunburn, as this was the highest exposure level reported in the majority of papers. The Los Angeles Multiethnic Cohort provided the prevalence of sunburn and red or blonde hair color in Hispanics and NHWs [15]. Prevalence of additional phenotypic characteristics and large nevi was obtained from the California Twin Program [16]. For phototype and chronic sun exposure, estimates were used from the National Health and Nutritional Examination Surveys (NHANES) and the National Health Interview Survey (NHIS) [17, 19]. Lastly, because of the lack of population-based prevalence information on sun exposure and counts of common nevi, we calculated a weighted average of the prevalence reported among controls of the included population-based studies.

We used the reported RR for each melanoma risk factor and the risk factor prevalence among Hispanics, to calculate the expected rate of melanoma incidence among Hispanics, and the ratio compared to that in NHWs. We present the rate ratio using an incidence rate of 29 per 100,000 in NHWs (observed in males in California), for which the comparable observed rate ratio is 7.25 (the comparable melanoma incidence rate in Hispanic males in California is approximately 4 per 100,000) [3].

Because so little data are available on the RR of melanoma risk factors specific to Hispanic populations, we have assumed that the RR in Hispanics is the same as in NHWs (discussed below). Where prevalence of risk factors was unknown in Hispanic populations, we could not calculate the expected rate ratio.

\section{Results and Discussion}

3.1. Does the Prevalence of Melanoma Risk Factor Phenotypes Explain the Lower Rate of Melanoma in Hispanics? Table 1 summarizes the risk factors, RR ranges, prevalence ranges, and calculated rate ratios [15-19, 24-95]. Of the risk factors for which an expected rate ratio could be calculated, skin phototype I or II was responsible for the highest expected rate ratio, but this was only 1.40 . Blonde hair was associated with the second highest expected rate ratio (1.26) in NHWs compared to Hispanics. Having many large nevi, although carrying RR of 3.05, demonstrated an expected rate ratio of 1.04 (because the prevalence of large nevi is similar in NHW and Hispanics), and high chronic sun exposure accounted for no difference in expected melanoma rates between Hispanics and NHWs. In both cases the expected rate ratio was near null because of the similarity of prevalence of the risk factor in Hispanics and NHWs. 
TABLE 1: Summary of relative risks (RR) and prevalence of risk factors.

\begin{tabular}{|c|c|c|c|c|c|c|c|c|}
\hline \multirow{2}{*}{ Risk factor } & \multirow{2}{*}{ Category } & \multirow{2}{*}{$\mathrm{RR}^{\mathrm{a}}$} & \multirow{2}{*}{$95 \% \mathrm{CI}$} & \multirow{2}{*}{$\mathrm{RR}$ range } & \multicolumn{2}{|c|}{ Prevalence (\%) } & \multirow{2}{*}{$\begin{array}{c}\begin{array}{c}\text { Expected rate } \\
\text { ratio }^{\mathrm{b}}\end{array} \\
\text { (Observed }=7.25)\end{array}$} & \multirow{2}{*}{ Source } \\
\hline & & & & & NHW & Hispanic & & \\
\hline \multirow{2}{*}{ Hair color } & Blonde & 1.96 & $1.41-2.72$ & $0.45-4.13$ & $13.60-46.80$ & $0.90-3.60$ & 1.26 & $\begin{array}{l}\text { Park et al., } 2012 \text { [15] } \\
\text { Cockburn et al., } 2007 \\
{[16], \text { CTP }^{c}}\end{array}$ \\
\hline & Red & 3.64 & $2.56-5.37$ & $1.73-4.94$ & $3.10-3.20$ & $0.30-1.30$ & 1.06 & $\begin{array}{l}\text { Park et al., } 2012 \text { [15] } \\
\text { Cockburn et al., } 2007 \\
{[16], \text { CTP }}\end{array}$ \\
\hline \multirow{3}{*}{ Phototype } & Fitzpatrick type I & 2.09 & $1.67-2.58$ & $2.36-2.64$ & $5.00-7.60$ & $1.00-3.30$ & 1.04 & $\begin{array}{l}\text { Lin et al., } 2012 \text { [17] } \\
\text { Galindo et al., } 2007 \\
{[8]}\end{array}$ \\
\hline & Fitzpatrick type II & 1.84 & $1.43-2.36$ & $1.82-4.13$ & $26.70-39.00$ & $10.70-12.00$ & 1.16 & $\begin{array}{l}\text { Lin et al., } 2012 \text { [17] } \\
\text { Galindo et al., } 2007 \\
{[8]}\end{array}$ \\
\hline & $\begin{array}{c}\text { Fitzpatrick type I } \\
\text { or II }\end{array}$ & 2.99 & $1.75-5.12$ & $1.31-2.90$ & $34.30-44.00$ & $13.00-14.00$ & 1.40 & $\begin{array}{l}\text { Lin et al., } 2012 \text { [17] } \\
\text { Galindo et al., } 2007 \\
{[8]}\end{array}$ \\
\hline Freckles & Many freckles & 2.10 & $1.80-2.45$ & $1.55-3.72$ & $\begin{array}{c}7.43 \\
\text { (controls) } \\
\end{array}$ & $\begin{array}{c}\text { Not } \\
\text { available }\end{array}$ & $\sim$ & \\
\hline \multirow{2}{*}{ Nevi } & Many nevi & 4.82 & $3.05-7.62$ & $1.50-6.50$ & $\begin{array}{c}11.66 \\
\text { (controls) }\end{array}$ & $\begin{array}{c}\text { Not } \\
\text { available }\end{array}$ & $\sim$ & \\
\hline & Many large nevi & 3.05 & & $1.19-5.70$ & 5.70 & 3.60 & 1.04 & CTP \\
\hline \multirow{4}{*}{ Sunburn } & $\begin{array}{l}\text { Many sunburns } \\
\text { (lifetime) }\end{array}$ & 2.03 & $1.73-2.37$ & $0.59-8.48$ & $7.50-20.70$ & $3.80-4.00$ & 1.10 & $\begin{array}{l}\text { Park et al., } 2012 \text { [15] } \\
\text { CHIS } 2009 \text { [18] }\end{array}$ \\
\hline & $\begin{array}{l}\text { Many sunburns } \\
\text { (childhood) }\end{array}$ & 2.24 & $1.73-2.89$ & $1.00-6.22$ & $\begin{array}{c}13.70 \\
\text { (controls) }\end{array}$ & $\begin{array}{c}\text { Not } \\
\text { available }\end{array}$ & $\sim$ & \\
\hline & $\begin{array}{l}\text { Ever had sunburn } \\
\quad \text { (lifetime) }\end{array}$ & 1.21 & & $1.10-5.70$ & 61.8 & 21 & 1.08 & Park et al., 2012 [15] \\
\hline & $\begin{array}{l}\text { Ever had sunburn } \\
\text { (childhood) }\end{array}$ & 1.47 & & $0.90-3.56$ & $\begin{array}{c}28.19 \\
\text { (controls) }\end{array}$ & $\begin{array}{c}\text { Not } \\
\text { available }\end{array}$ & $\sim$ & \\
\hline \multirow{3}{*}{ Sun exposure } & $\begin{array}{l}\text { High total lifetime } \\
\text { sun exposure }\end{array}$ & 1.34 & $1.02-1.77$ & $0.80-4.34$ & $\begin{array}{c}27.11 \\
\text { (controls) }\end{array}$ & $\begin{array}{c}\text { Not } \\
\text { available }\end{array}$ & $\sim$ & \\
\hline & $\begin{array}{l}\text { High intermittent } \\
\text { sun exposure }\end{array}$ & 1.61 & $1.31-1.99$ & $0.65-5.00$ & $\begin{array}{c}40.54 \\
\text { (controls) }\end{array}$ & $\begin{array}{c}\text { Not } \\
\text { available }\end{array}$ & $\sim$ & \\
\hline & $\begin{array}{l}\text { High chronic sun } \\
\text { exposure }\end{array}$ & 0.95 & $0.87-1.04$ & $0.33-2.57$ & $\begin{array}{c}5.44 \\
\text { (controls) }\end{array}$ & 12.00 & 1.00 & Coups et al., 2012 [19] \\
\hline
\end{tabular}

${ }^{a}$ RR represents summary statistic from meta-analysis by Gandini et al., 2005 [20-22] (I, II, and III) or median of RR range where summary statistic is not reported.

${ }^{b}$ Expected ratio of incidence rates (NHW/Hispanic) based on prevalence of risk factor in each population and RR provided. Median prevalence value is used when a range is provided.

${ }^{c}$ CTP: California Twin Program; prevalence data for NHWs is described by Cockburn et al., 2007 [16], and prevalence data for Hispanics comes from the same data set.

$\sim$ Expected rate ratio cannot be calculated because prevalence in Hispanics is unknown.

Most studies comparing rates of melanoma in Hispanics and NHWs focus on delayed diagnosis and overall worse outcomes among Hispanics, while few specifically compare risk factors. Our review confirms that Hispanics do have lower prevalence of some of the major melanoma risk phenotypes, blonde or red hair color, Fitzpatrick skin type I or II, strong history of sunburn, and many large nevi. However, these risk factors are not sufficiently rare in Hispanics to explain their lower rate of melanoma compared to NHWs, largely because there is overlap in the prevalence of the risk factors between Hispanics and NHWs.
3.2. Could Sun Exposure Behavior Explain the Lower Rate of Melanoma in Hispanics? Hispanics may have a reduced melanoma risk if they practice better sun protection. Recent studies highlight differences in method of sun protection among subpopulations of Hispanics. Specifically, Englishacculturated Hispanics display more sunscreen use but less use of sun protective clothing, while Spanish-acculturated Hispanics are more likely to wear sun protective clothing without sunscreen $[19,96]$. Additionally, English-acculturated Hispanics are more likely to have had a sunburn in the past year compared to those less acculturated, consistent 
with data showing that sunscreen may not be as effective as sun protective clothing at preventing sunburn $[19,97]$. Given the diversity of sun protective practices among Hispanics, studying the relationship between sun exposure behavior and melanoma stratified by level of acculturation would help clarify whether safer sun exposure behavior accounts for overall low rates of melanoma in this population.

Data from the Behavioral Risk Factor Surveillance System (BRFSS) shows that overall a smaller percentage of Hispanics reported having at least one sunburn in the preceding year compared to NHWs. Hispanics who reported having at least one sunburn in the past year were more likely to have had only one sunburn, compared to NHWs [98]. However, BRFSS data also show that sunburn among Hispanics is relatively common, which could contribute to their increasing incidence of melanoma. Compared to NHWs, Hispanics do have higher prevalence of chronic sun exposure, shown to be protective against melanoma compared to intermittent exposure $[9,10$, 99].

\subsection{Could Genetic Effects Explain the Lower Rate of Melanoma} in Hispanics? A multitude of genetic factors, if substantially different in the two populations, could either protect Hispanics or make NHWs more susceptible to melanoma. Six loci have been implicated in melanoma susceptibility. While five of them represent genes involved in melanin production (MC1R, TYR, TYRP1, SLC45A2, and ASIP), the sixth locus is thought to represent two genes, both involved in nevus formation (CDKN2A and MTAP) $[10,100]$. The CDKN2A gene is inherited in an autosomal dominant fashion and is associated with familial melanoma, which represents only 5 to $12 \%$ of melanoma cases [101]. The prevalence of these genotypes in Hispanics is unknown.

The MC1R gene codes for the melanocortin-1 receptor. Weak signaling of this receptor due to inactivating polymorphisms in the MC1R gene results in production of the red pigment pheomelanin ("red hair/fair skin" phenotype), instead of the brown/black eumelanin [102]. It has recently been shown that pheomelanin may be carcinogenic itself, independent of UV radiation, particularly in the context of an activating mutation in the kinase BRAF (the most common driver mutation in melanoma). Specifically, mice with an inactivating $M C 1 R$ mutation and the BRAF mutation had red fur and developed melanoma, while mice who did not produce pheomelanin did not develop melanoma, despite having the BRAF mutation [103]. However, given the overlap in skin types between Hispanics and NHWs and the nearnull expected rate ratio for skin type in our analysis, variations in the population prevalence of MC1R inactivating polymorphisms and pheomelanin are unlikely to fully explain the large difference in melanoma incidence.

$B R A F$ mutations are more common in melanomas occurring in skin intermittently exposed to high amounts of sun compared with melanomas arising on unexposed or chronically exposed skin [104]. It is possible that fewer Hispanics have $B R A F$ mutations, which could help to explain their lower incidence of melanoma. Since most clinical trials have been conducted in NHWs, there is a paucity of literature on genetic mutations in other populations [105]. Further studies are necessary to elucidate the role of genotype in the risk for melanoma among Hispanics.

3.4. Limitations. The observation that Hispanics have more advanced melanomas at diagnosis than NHWs could be explained by lower awareness of melanoma in this population, resulting in lower likelihood of seeking care [106-109]. This presents the possibility that true rates of melanoma in the Hispanic population are higher than observed and that there is poorer detection of cases. However, 35.4 percent of tumors in Hispanic males in California are "thick" (>1.5 mm) at diagnosis, compared with 24.4 percent of tumors in NHWs, so the lack of detection of thin tumors through screening in Hispanics alone is unlikely to explain a 7-fold difference in the overall incidence rate [2].

We make a number of assumptions in our calculations, which are done for illustrative purposes. First, we assume that the RR for each risk factor is the same in Hispanics and NHWs. This is because there is little data assessing melanoma risk factors specifically in Hispanics. It is possible that RRs for melanoma risk factors differ for NHWs and Hispanics but that remains to be shown. For illustrative purposes, we have used incidence data only from NHW and Hispanic males in California, but the rate ratios for comparison among females in California provide similar results. Finally, we considered all invasive melanomas together, though the distributions of the various melanoma histologic subtypes are known to differ between NHW and Hispanics [5, 9]. However, risk factors for nodular and superficial spreading melanoma do not vary among NHWs, and there is limited data on other histologyspecific risk factors [110].

\section{Conclusions}

To determine effective methods of primary prevention, it is useful to investigate characteristics associated with lower risk of melanoma. To that end, the melanoma experience of Hispanics, who have at least 7-fold lower risk of melanoma than NHWs, might provide clues to improved melanoma prevention. This review highlights the limited data on melanoma risk phenotypes in Hispanic populations; what is currently known about the differences in their prevalence between Hispanics and NHWs inadequately explains a 7-fold difference in melanoma rates.

While genotype may vary between Hispanics and NHWs, there is insufficient data about melanoma risk genes in Hispanic populations to attribute their lower melanoma rates to genetic factors alone. The association between genotype and melanoma risk phenotype might lead us to expect greater differences in skin type and nevi prevalence between Hispanics and NHWs if differentially expressed genetic factors explained the 7-fold difference in melanoma incidence.

While little data exist comparing sun exposure behaviors in Hispanics and NHWs, current data show that Hispanics sunburn less frequently. If sun exposure behaviors help protect Hispanics from melanoma, there could be great potential for improving prevention in all populations through behavioral change. Once the sun exposure behaviors of Hispanics are more clearly understood, prevention messages might be 
improved. The lower rate of melanoma in Hispanics should be formally investigated in future studies, providing direct comparison of measured risk factors in Hispanics versus NHWs and accounting for any differences in sun exposure behaviors, phenotypic and genotypic characteristics. Such an approach may better inform our methods of melanoma prevention in both Hispanics and NHWs.

\section{Disclosure}

The ideas and opinions expressed herein are those of the author(s) and endorsement by the State of California, Department of Public Health the National Cancer Institute, and the Centers for Disease Control and Prevention or their Contractors and Subcontractors is not intended nor should be inferred.

\section{Competing Interests}

The authors declare that there are no competing interests regarding the publication of this paper.

\section{Acknowledgments}

Dr. Myles G. Cockburn was supported in part by the National Cancer Institute's Surveillance, Epidemiology and End Results Program under Contract HHSN261201000140C awarded to the Cancer Prevention Institute of California, Contract HHSN261201000035C awarded to the University of Southern California, and Contract HHSN261201000034C awarded to the Public Health Institute and the Centers for Disease Control and Prevention's National Program of Cancer Registries, under Agreement U58DP003862-01 awarded to the California Department of Public Health.

\section{References}

[1] US Census Bureau, Hispanics in the United States, 2008, http:// www.census.gov/population/hispanic/publications/hispanics_ 2006.html.

[2] M. G. Cockburn, J. Zadnick, and D. Deapen, "Developing epidemic of melanoma in the Hispanic population of California," Cancer, vol. 106, no. 5, pp. 1162-1168, 2006.

[3] R. A. Pollitt, C. A. Clarke, S. M. Swetter, D. H. Peng, J. Zadnick, and M. Cockburn, "The expanding melanoma burden in California Hispanics," Cancer, vol. 117, no. 1, pp. 152-161, 2011.

[4] US Census Bureau, State \& County Quick Facts-California, 2012, http://quickfacts.census.gov/qfd/states/06000.html.

[5] R. D. Cress and E. A. Holly, "Incidence of cutaneous melanoma among non-Hispanic Whites, Hispanics, Asians, and blacks: an analysis of California Cancer Registry Data, 1988-93," Cancer Causes and Control, vol. 8, no. 2, pp. 246-252, 1997.

[6] X.-C. Wu, M. J. Eide, J. King et al., "Racial and ethnic variations in incidence and survival of cutaneous melanoma in the United States, 1999-2006," Journal of the American Academy of Dermatology, vol. 65, no. 5, supplement 1, pp. S26-S37, 2011.

[7] R. M. Merrill, N. D. Pace, and A. N. Elison, "Cutaneous malignant melanoma among white Hispanics and non-Hispanics in the United States," Ethnicity \& Disease, vol. 20, no. 4, pp. 353358, 2010.

[8] G. R. Galindo, J. A. Mayer, D. Slymen et al., "Sun sensitivity in 5 US ethnoracial groups," Cutis, vol. 80, no. 1, pp. 25-30, 2007.

[9] S. Hu, F. Ma, F. Collado-Mesa, and R. S. Kirsner, "UV radiation, latitude, and melanoma in US Hispanics and blacks," Archives of Dermatology, vol. 140, no. 7, pp. 819-824, 2004.

[10] S. T. Chen, A. C. Geller, and H. Tsao, "Update on the epidemiology of melanoma," Current Dermatology Reports, vol. 2, no. 1, pp. 24-34, 2013.

[11] M. A. Tucker, "Melanoma epidemiology," Hematology/Oncology Clinics of North America, vol. 23, no. 3, pp. 383-395, 2009.

[12] N. Jaimes, S. Oliveria, and A. Halpern, "A cautionary note on melanoma screening in the Hispanic/Latino population," JAMA Dermatology, vol. 149, no. 4, pp. 396-397, 2013.

[13] C. M. Olsen, H. J. Carroll, and D. C. Whiteman, "Estimating the attributable fraction for cancer: a meta-analysis of nevi and melanoma," Cancer Prevention Research, vol. 3, no. 2, pp. 233$245,2010$.

[14] C. M. Olsen, H. J. Carroll, and D. C. Whiteman, "Estimating the attributable fraction for melanoma: a meta-analysis of pigmentary characteristics and freckling," International Journal of Cancer, vol. 127, no. 10, pp. 2430-2445, 2010.

[15] S. L. Park, L. Le Marchand, L. R. Wilkens et al., "Risk factors for malignant melanoma in white and non-white/non-African American populations: the multiethnic cohort," Cancer Prevention Research, vol. 5, no. 3, pp. 423-434, 2012.

[16] M. G. Cockburn, A. Hamilton, and T. Mack, "The simultaneous assessment of constitutional, behavioral, and environmental factors in the development of large nevi," Cancer Epidemiology Biomarkers and Prevention, vol. 16, no. 2, pp. 200-206, 2007.

[17] F. R. Lin, P. Maas, W. Chien, J. P. Carey, L. Ferrucci, and R. Thorpe, "Association of skin color, race/ethnicity, and hearing loss among adults in the USA," Journal of the Association for Research in Otolaryngology, vol. 13, no. 1, pp. 109-117, 2012.

[18] California Health Interview Survey, 2009, http://ask.chis.ucla .edu.

[19] E. J. Coups, J. L. Stapleton, S. V. Hudson, A. Medina-Forrester, A. Natale-Pereira, and J. S. Goydos, "Sun protection and exposure behaviors among Hispanic adults in the United States: differences according to acculturation and among Hispanic subgroups," BMC Public Health, vol. 12, pp. 985-993, 2012.

[20] S. Gandini, F. Sera, M. S. Cattaruzza et al., "Meta-analysis of risk factors for cutaneous melanoma: I. Common and atypical naevi," European Journal of Cancer, vol. 41, no. 1, pp. 28-44, 2005.

[21] S. Gandini, F. Sera, M. S. Cattaruzza et al., "Meta-analysis of risk factors for cutaneous melanoma: II. Sun exposure," European Journal of Cancer, vol. 41, no. 1, pp. 45-60, 2005.

[22] S. Gandini, F. Sera, M. S. Cattaruzza et al., "Meta-analysis of risk factors for cutaneous melanoma: III. Family history, actinic damage and phenotypic factors," European Journal of Cancer, vol. 41, no. 14, pp. 2040-2059, 2005.

[23] A. M. Goldstein and M. A. Tucker, "Dysplastic nevi and melanoma," Cancer Epidemiology Biomarkers and Prevention, vol. 22, no. 4, pp. 528-532, 2013.

[24] A. A. Qureshi, M. Zhang, and J. Han, "Heterogeneity in host risk factors for incident melanoma and non-melanoma skin cancer in a cohort of US women," Journal of Epidemiology, vol. 21, no. 3, pp. 197-203, 2011. 
[25] J. Han, G. A. Colditz, and D. J. Hunter, "Risk factors for skin cancers: a nested case-control study within the Nurses' Health Study," International Journal of Epidemiology, vol. 35, no. 6, pp. 1514-1521, 2006.

[26] J. Wendt, O. Schanab, M. Binder, H. Pehamberger, and I. Okamoto, "Site-dependent actinic skin damage as risk factor for melanoma in a central European population," Pigment Cell and Melanoma Research, vol. 25, no. 2, pp. 234-242, 2012.

[27] E. De Vries, M. Trakatelli, D. Kalabalikis et al., "Known and potential new risk factors for skin cancer in European populations: a multicentre case-control study," British Journal of Dermatology, vol. 167, no. 2, pp. 1-13, 2012.

[28] O. C. Luiz, R. J. Gianini, F. T. Gonçalves et al., "Ethnicity and cutaneous melanoma in the city of Sao Paulo, Brazil: a casecontrol study," PLoS ONE, vol. 7, no. 4, Article ID e36348, 2012.

[29] C. Fortes, S. Mastroeni, P. Boffetta et al., "Polymorphisms of GSTM1 and GSTT1, sun exposure and the risk of melanoma: a case-control study," Acta Dermato-Venereologica, vol. 91, no. 3, pp. 284-289, 2011.

[30] A. E. Cust, M. A. Jenkins, C. Goumas et al., "Early-life sun exposure and risk of melanoma before age 40 years," Cancer Causes and Control, vol. 22, no. 6, pp. 885-897, 2011.

[31] J. A. Newton-Bishop, Y.-M. Chang, F. Elliott et al., "Relationship between sun exposure and melanoma risk for tumours in different body sites in a large case-control study in a temperate climate," European Journal of Cancer, vol. 47, no. 5, pp. 732-741, 2011.

[32] D. Lazovich, R. I. Vogel, M. Berwick, M. A. Weinstock, K. E. Anderson, and E. M. Warshaw, "Indoor tanning and risk of melanoma: a case-control study in a highly exposed population," Cancer Epidemiology Biomarkers and Prevention, vol. 19, no. 6, pp. 1557-1568, 2010.

[33] L. K. Dennis, C. F. Lynch, D. P. Sandler, and M. C. R. Alavanja, "Pesticide use and cutaneous melanoma in pesticide applicators in the agricultural heath study," Environmental Health Perspectives, vol. 118, no. 6, pp. 812-817, 2010.

[34] M. B. Veierød, H.-O. Adami, E. Lund, B. K. Armstrong, and E. Weiderpass, "Sun and solarium exposure and melanoma risk: effects of age, pigmentary characteristics, and nevi," Cancer Epidemiology Biomarkers and Prevention, vol. 19, no. 1, pp. 111$120,2010$.

[35] A. Chiarugi, M. Ceroti, D. Palli, G. Cevenini, M. Guarrera, and P. Carli, "Sensitivity to ultraviolet B is a risk factor for cutaneous melanoma in a Mediterranean population: results from an Italian case-control study," Clinical and Experimental Dermatology, vol. 34, no. 1, pp. 8-15, 2009.

[36] A. E. Cust, H. Schmid, J. A. Maskiell et al., "Populationbased, case-control-family design to investigate genetic and environmental influences on melanoma risk," American Journal of Epidemiology, vol. 170, no. 12, pp. 1541-1554, 2009.

[37] C. Li, Z. Liu, L. E. Wang et al., "Haplotype and genotypes of the VDR gene and cutaneous melanoma risk in non-Hispanic whites in Texas: a case-control study," International Journal of Cancer, vol. 122, no. 9, pp. 2077-2084, 2008.

[38] V. A. Nikolaou, V. Sypsa, I. Stefanaki et al., "Risk associations of melanoma in a Southern European population: results of a case/control study," Cancer Causes and Control, vol. 19, no. 7, pp. 671-679, 2008.

[39] S. Rosso, R. Zanetti, M. J. Sánchez et al., "Is 2,3,5-pyrroletricarboxylic acid in hair a better risk indicator for melanoma than traditional epidemiologic measures for skin phenotype?"
American Journal of Epidemiology, vol. 165, no. 10, pp. 1170-1177, 2007.

[40] C. S. Mantzoros, M. Trakatelli, H. Gogas et al., "Circulating adiponectin levels in relation to melanoma: a case-control study," European Journal of Cancer, vol. 43, no. 9, pp. 1430-1436, 2007.

[41] C. S. Lea, J. A. Scotto, P. A. Buffler, J. Fine, R. L. Barnhill, and M. Berwick, "Ambient UVB and melanoma risk in the United States: a case-control analysis," Annals of Epidemiology, vol. 17, no. 6, pp. 447-453, 2007.

[42] R. Zanetti, S. Rosso, C. Martinez et al., "Comparison of risk patterns in carcinoma and melanoma of the skin in men: a multi-centre case-case-control study," British Journal of Cancer, vol. 94, no. 5, pp. 743-751, 2006.

[43] Z. Tatalovich, J. P. Wilson, T. Mack, Y. Yan, and M. Cockburn, "The objective assessment of lifetime cumulative ultraviolet exposure for determining melanoma risk," Journal of Photochemistry and Photobiology B, vol. 85, no. 3, pp. 198-204, 2006.

[44] A. R. Shors, S. Kim, E. White et al., "Dysplastic naevi with moderate to severe histological dysplasia: a risk factor for melanoma," British Journal of Dermatology, vol. 155, no. 5, pp. 988-993, 2006.

[45] L. Naldi, G. Randi, A. Di Landro, and C. L. Vecchia, "Red hairs, number of nevi, and risk of cutaneous malignant melanoma: results from a case-control study in Italy," Archives of Dermatology, vol. 142, no. 7, pp. 935-936, 2006.

[46] T. Nijsten, C. Leys, K. Verbruggen et al., "Case-control study to identify melanoma risk factors in the Belgian population: the significance of clinical examination," Journal of the European Academy of Dermatology and Venereology, vol. 19, no. 3, pp. 332339, 2005.

[47] E. De Vries, M. Boniol, G. Severi et al., "Public awareness about risk factors could pose problems for case-control studies: the example of sunbed use and cutaneous melanoma," European Journal of Cancer, vol. 41, no. 14, pp. 2150-2154, 2005.

[48] L.-E. Wang, P. Xiong, S. S. Strom et al., "In vitro sensitivity to ultraviolet B light and skin cancer risk: a case-control analysis," Journal of the National Cancer Institute, vol. 97, no. 24, pp. 18221831, 2005.

[49] L. Naldi, A. Altieri, G. L. Imberti, L. Giordano, S. Gallus, and C. La Vecchia, "Cutaneous malignant melanoma in women. Phenotypic characteristics, sun exposure, and hormonal factors: a case-control study from Italy," Annals of Epidemiology, vol. 15, no. 7, pp. 545-550, 2005.

[50] L. Titus-Ernstoff, A. E. Perry, S. K. Spencer, J. J. Gibson, B. F. Cole, and M. S. Ernstoff, "Pigmentary characteristics and moles in relation to melanoma risk," International Journal of Cancer, vol. 116, no. 1, pp. 144-149, 2005.

[51] V. Bataille, M. Boniol, E. De Vries et al., "A multicentre epidemiological study on sunbed use and cutaneous melanoma in Europe," European Journal of Cancer, vol. 41, no. 14, pp. 21412149, 2005.

[52] K. Lasithiotakis, S. Krüger-Krasagakis, D. Ioannidou, I. Pediaditis, and A. Tosca, "Epidemiological differences for cutaneous melanoma in a relatively dark-skinned caucasian population with chronic sun exposure," European Journal of Cancer, vol. 40, no. 16, pp. 2502-2507, 2004.

[53] M. C. Fargnoli, D. Piccolo, E. Altobelli, F. Formicone, S. Chimenti, and K. Peris, "Constitutional and environmental risk factors for cutaneous melanoma in an Italian population: a casecontrol study," Melanoma Research, vol. 14, no. 2, pp. 151-157, 2004 . 
[54] D. M. Freedman, A. Sigurdson, R. S. Rao et al., "Risk of melanoma among radiologic technologists in the United States," International Journal of Cancer, vol. 103, no. 4, pp. 556-562, 2003.

[55] Q. Wei, J. E. Lee, J. E. Gershenwald et al., "Repair of UV light-induced DNA damage and risk of cutaneous malignant melanoma," Journal of the National Cancer Institute, vol. 95, no. 4, pp. 308-315, 2003.

[56] A. C. Geller, A. J. Sober, Z. Zhang et al., "Strategies for improving melanoma education and screening for men age $\geq$ 50 years: gindings from the American Academy of Dermatology National Skin Cancer Screening Program," Cancer, vol. 95, no. 7, pp. 1554-1561, 2002.

[57] L. Bakos, M. Wagner, R. M. Bakos et al., "Sunburn, sunscreens, and phenotypes: some risk factors for cutaneous melanoma in southern Brazil," International Journal of Dermatology, vol. 41, no. 9, pp. 557-562, 2002.

[58] D. Loria and E. Matos, "Risk factors for cutaneous melanoma: a case-control study in Argentina," International Journal of Dermatology, vol. 40, no. 2, pp. 108-114, 2001.

[59] T. Dwyer, L. Blizzard, R. Ashbolt, J. Plumb, M. Berwick, and J. M. Stankovich, "Cutaneous melanin density of caucasians measured by spectrophotometry and risk of malignant melanoma, basal cell carcinoma, and squamous cell carcinoma of the skin," American Journal of Epidemiology, vol. 155, no. 7, pp. 614-621, 2002.

[60] A. R. Shors, C. Solomon, A. McTiernan, and E. White, "Melanoma risk in relation to height, weight, and exercise (United States)," Cancer Causes and Control, vol. 12, no. 7, pp. 599-606, 2001.

[61] M. T. Landi, A. Baccarelli, D. Calista et al., "Combined risk factors for melanoma in a Mediterranean population," British Journal of Cancer, vol. 85, no. 9, pp. 1304-1310, 2001.

[62] P. Kaskel, S. Sander, M. Kron, P. Kind, R. U. Peter, and G. Krähn, "Outdoor activities in childhood: a protective factor for cutaneous melanoma? Results of a case-control study in 271 matched pairs," British Journal of Dermatology, vol. 145, no. 4, pp. 602-609, 2001.

[63] A. Pfahlberg, K.-F. Kölmel, and O. Gefeller, “Timing of excessive ultraviolet radiation and melanoma: Epidemiology does not support the existence of a critical period of high susceptibility to solar ultraviolet radiation-induced melanoma," British Journal of Dermatology, vol. 144, no. 3, pp. 471-475, 2001.

[64] N. Håkansson, B. Floderus, P. Gustavsson, M. Feychting, and N. Hallin, "Occupational sunlight exposure and cancer incidence among Swedish construction workers," Epidemiology, vol. 12, no. 5, pp. 552-557, 2001.

[65] L. Naldi, G. L. Imberti, F. Parazzini et al., "Pigmentary traits, modalities of sun reaction, history of sunburns, and melanocytic nevi as risk factors for cutaneous malignant melanoma in the Italian population: results of a collaborative case-control study," Cancer, vol. 88, no. 12, pp. 2703-2710, 2000.

[66] G. Mastrangelo, C. R. Rossi, A. Pfahlberg et al., "Is there a relationship between influenza vaccinations and risk of melanoma? A population-based case-control study," European Journal of Epidemiology, vol. 16, no. 9, pp. 777-782, 2000.

[67] S. D. Walter, W. D. King, and L. D. Marrett, "Association of cutaneous malignant melanoma with intermittent exposure to ultraviolet radiation: results of a case-control study in Ontario, Canada," International Journal of Epidemiology, vol. 28, no. 3, pp. 418-427, 1999.
[68] S. Rosso, R. Zanetti, M. Pippione, and H. Sancho-Garnier, "Parallel risk assessment of melanoma and basal cell carcinoma: skin characteristics and sun exposure," Melanoma Research, vol. 8, no. 6, pp. 573-583, 1998.

[69] P. Wolf, F. Quehenberger, R. Müllegger, B. Stranz, and H. Kerl, "Phenotypic markers, sunlight-related factors and sunscreen use in patients with cutaneous melanoma: an Austrian casecontrol study," Melanoma Research, vol. 8, no. 4, pp. 370-378, 1998.

[70] M. A. Tucker, A. Halpern, E. A. Holly et al., "Clinically recognized dysplastic nevi: a central risk factor for cutaneous melanoma," The Journal of the American Medical Association, vol. 277, no. 18, pp. 1439-1444, 1997.

[71] J. M. Ródenas, M. Delgado-Rodríguez, C. Fariñas-Álvarez, M. T. Herranz, and S. Serrano, "Melanocytic nevi and risk of cutaneous malignant melanoma in southern Spain," American Journal of Epidemiology, vol. 145, no. 11, pp. 1020-1029, 1997.

[72] A. E. Grulich, V. Bataille, A. J. Swerdlow et al., "Naevi and pigmentary characteristics as risk factors for melanoma in a high-risk population: a case-control study in New South Wales, Australia," International Journal of Cancer, vol. 67, no. 4, pp. 485-491, 1996.

[73] V. Bataille, J. A. Newton Bishop, P. Sasieni et al., "Risk of cutaneous melanoma in relation to the numbers, types and sites of naevi: a case-control study," British Journal of Cancer, vol. 73, no. 12, pp. 1605-1611, 1996.

[74] K. J. Goodman, M. L. Bible, S. London, and T. M. Mack, "Proportional melanoma incidence and occupation among white males in Los Angeles County (California, United States)," Cancer Causes and Control, vol. 6, no. 5, pp. 451-459, 1995.

[75] J. Westerdahl, H. Olsson, A. Masback, C. Ingvar, and N. Jonsson, "Is the use of sunscreens a risk factor for malignant melanoma?" Melanoma Research, vol. 5, no. 1, pp. 59-65, 1995.

[76] P. Autier, J. F. Dore, F. Lejeune et al. et al., "Recreational exposure to sunlight and lack of information as risk factors for cutaneous malignant melanoma. Results of an European Organization for Research and Treatment of Cancer (EORTC) case-control study in Belgium, France and Germany. The EORTC Malignant Melanoma Cooperative Group," Melanoma Research, vol. 4, no. 2, pp. 79-85, 1994.

[77] P. J. Nelemans, H. Groenendal, L. A. L. M. Kiemeney, F. H. J. Rampen, D. J. Ruiter, and A. L. M. Verbeek, "Effect of intermittent exposure to sunlight on melanoma risk among indoor workers and sun-sensitive individuals," Environmental Health Perspectives, vol. 101, no. 3, pp. 252-255, 1993.

[78] L. D. Marrett, W. D. King, S. D. Walter, and L. From, "Use of host factors to identify people at high risk for cutaneous malignant melanoma," Canadian Medical Association Journal, vol. 147, no. 4, pp. 445-453, 1992.

[79] D. Zaridze, A. Mukeria, and S. W. Duffy, "Risk factors for skin melanoma in Moscow," International Journal of Cancer, vol. 52, no. 1, pp. 159-161, 1992.

[80] J. Weiss, J. Bertz, and E. G. Jung, "Malignant melanoma in southern Germany: different predictive value of risk factors for melanoma subtypes," Dermatologica, vol. 183, no. 2, pp. 109-113, 1991.

[81] J. M. Elwood, S. M. Whitehead, J. Davison, M. Stewart, and M. Galt, "Malignant melanoma in England: risks associated with naevi, freckles, social class, hair colour, and sunburn," International Journal of Epidemiology, vol. 19, no. 4, pp. 801-810, 1990. 
[82] N. Dubin, B. S. Pasternack, and M. Moseson, "Simultaneous assessment of risk factors for malignant melanoma and nonmelanoma skin lesions, with emphasis on sun exposure and related variables," International Journal of Epidemiology, vol. 19, no. 4, pp. 811-819, 1990.

[83] H. Beitner, S. E. Norell, U. Ringborg, G. Wennersten, and B. Mattson, "Malignant melanoma: aetiological importance of individual pigmentation and sun exposure," British Journal of Dermatology, vol. 122, no. 1, pp. 43-51, 1990.

[84] C. Garbe, S. Kruger, R. Stadler, I. Guggenmoos-Holzmann, and C. E. Orfanos, "Markers and relative risk in a German population for developing malignant melanoma," International Journal of Dermatology, vol. 28, no. 8, pp. 517-523, 1989.

[85] G. C. Roush, J. J. Nordlund, B. Forget, S. B. Gruber, and J. M. Kirkwood, "Independence of dysplastic nevi from total nevi in determining risk for nonfamilial melanoma," Preventive Medicine, vol. 17, no. 3, pp. 273-279, 1988.

[86] A. Osterlind, M. A. Tucker, K. Hou-Jensen, B. J. Stone, G. Engholm, and O. M. Jensen, "The Danish case-control study of cutaneous malignant melanoma. I. Importance of host factors," International Journal of Cancer, vol. 42, no. 2, pp. 200-206, 1988.

[87] E. A. Holly, J. W. Kelly, S. Shpall, and S.-H. Chiu, "Number of melanocytic nevi as a major risk factor for malignant melanoma," Journal of the American Academy of Dermatology, vol. 17, no. 3, pp. 459-468, 1987.

[88] C. M. J. Bell, C. M. Jenkinson, T. J. Murrells, R. G. Skeet, and J. D. Everall, "Aetiological factors in cutaneous malignant melanomas seen at a UK skin clinic," Journal of Epidemiology and Community Health, vol. 41, no. 4, pp. 306-311, 1987.

[89] M. Cristofolini, S. Franceschi, L. Tasin et al., "Risk factors for cutaneous malignant melanoma in a northern Italian population," International Journal of Cancer, vol. 39, no. 2, pp. 150-154, 1987.

[90] A. J. Swerdlow, J. English, R. M. MacKie et al., "Benign melanocytic naevi as a risk factor for malignant melanoma," British Medical Journal, vol. 292, no. 6535, pp. 1555-1559, 1986.

[91] A. Green, R. MacLennan, and V. Siskind, "Common acquired naevi and the risk of malignant melanoma," International Journal of Cancer, vol. 35, no. 5, pp. 297-300, 1985.

[92] C. D. J. Holman and B. K. Armstrong, "Pigmentary traits, ethnic origin, benign nevi, and family history as risk factors for cutaneous malignant melanoma," Journal of the National Cancer Institute, vol. 72, no. 2, pp. 257-266, 1984.

[93] J. M. Elwood, R. P. Gallagher, G. B. Hill, J. J. Spinelli, J. C. G. Pearson, and W. Threlfall, "Pigmentation and skin reaction to sun as risk factors for cutaneous melanoma: Western Canada Melanoma Study," British Medical Journal, vol. 288, no. 6411, pp. 99-102, 1984.

[94] V. Beral, S. Evans, H. Shaw, and G. Milton, "Cutaneous factors related to the risk of malignant melanoma," British Journal of Dermatology, vol. 109, no. 2, pp. 165-172, 1983.

[95] O. Klepp and K. Magnus, "Some environmental and bodily characteristics of melanoma patients. A case-control study," International Journal of Cancer, vol. 23, no. 4, pp. 482-486, 1979.

[96] V. A. Andreeva, J. B. Unger, A. L. Yaroch, M. G. Cockburn, L. Baezconde-Garbanati, and K. D. Reynolds, "Acculturation and sun-safe behaviors among US latinos: findings from the 2005 Health Information National Trends Survey," American Journal of Public Health, vol. 99, no. 4, pp. 734-741, 2009.

[97] E. Linos, E. Keiser, T. Fu, G. Colditz, S. Chen, and J. Y. Tang, "Hat, shade, long sleeves, or sunscreen? Rethinking US sun protection messages based on their relative effectiveness," Cancer Causes and Control, vol. 22, no. 7, pp. 1067-1071, 2011.

[98] Centers for Disease Control and Prevention, "Sunburn prevalence among adults-United States, 1999, 2003, and 2004," Morbidity and Mortality Weekly Report, vol. 56, no. 21, pp. 524528, 2007.

[99] D. Carroll, R. M. Samardich, S. Bernard, S. Gabbard, and T. Hernandez, "Findings from the national agricultural workers survey (NAWS) 2001-2002: a demographic and employment profile of United States farm workers," Research Report 9, US Department of Labor, Washington, DC, USA, 2005.

[100] M. H. Law, S. MacGregor, and N. K. Hayward, "Melanoma genetics: recent findings take us beyond well-traveled pathways," Journal of Investigative Dermatology, vol. 132, no. 7, pp. 1763-1774, 2012.

[101] A. M. Goldstein and M. A. Tucker, "Genetic epidemiology of cutaneous melanoma: a global perspective," Archives of Dermatology, vol. 137, no. 11, pp. 1493-1496, 2001.

[102] N. Flanagan, E. Healy, A. Ray et al., "Pleiotropic effects of the melanocortin 1 receptor (MC1R) gene on human pigmentation," Human Molecular Genetics, vol. 9, no. 17, pp. 2531-2537, 2000.

[103] D. Mitra, X. Luo, A. Morgan et al., "A UV-independent pathway to melanoma carcinogenesis in the redhair-fairskin background," Nature, vol. 491, no. 7424, pp. 449-453, 2012.

[104] J. L. Maldonado, J. Fridlyand, H. Patel et al., "Determinants of BRAF mutations in primary melanomas," Journal of the National Cancer Institute, vol. 95, no. 24, pp. 1878-1880, 2003.

[105] S. Y. Morita and S. N. Markovic, "Molecular targets in melanoma: time for 'ethnic personalization," Expert Review of Anticancer Therapy, vol. 12, no. 5, pp. 601-608, 2012.

[106] M. Pipitone, J. K. Robinson, C. Camara, B. Chittineni, and S. G. Fisher, "Skin cancer awareness in suburban employees: a hispanic perspective," Journal of the American Academy of Dermatology, vol. 47, no. 1, pp. 118-123, 2002.

[107] J. K. Robinson, K. M. Joshi, S. Ortiz, and R. V. Kundu, "Melanoma knowledge, perception, and awareness in ethnic minorities in Chicago: recommendations regarding education," Psycho-Oncology, vol. 20, no. 3, pp. 313-320, 2011.

[108] C. Roman, A. Lugo-Somolinos, and N. Thomas, "Skin cancer knowledge and skin self-examinations in the Hispanic population of North Carolina: the patient's perspective," JAMA Dermatology, vol. 149, no. 1, pp. 103-104, 2013.

[109] E. J. Coups, J. L. Stapleton, S. V. Hudson et al., "Skin cancer surveillance behaviors among US Hispanic adults," Journal of the American Academy of Dermatology, vol. 68, no. 4, pp. 576584, 2013.

[110] B. Langholz, J. Richardson, E. Rappaport, J. Waisman, M. Cockburn, and T. Mack, "Skin characteristics and risk of superficial spreading and nodular melanoma (United States)," Cancer Causes and Control, vol. 11, no. 8, pp. 741-750, 2000. 


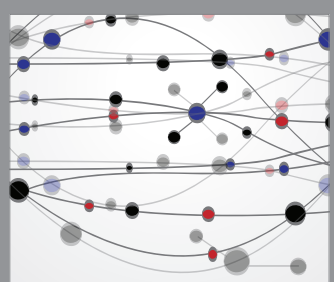

The Scientific World Journal
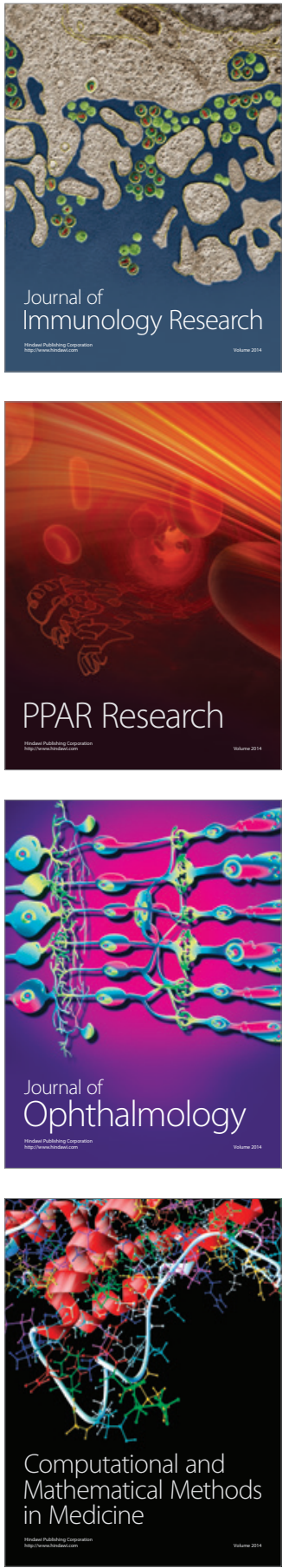

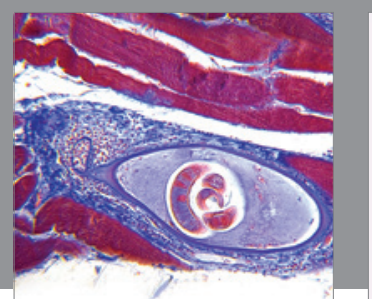

Gastroenterology Research and Practice

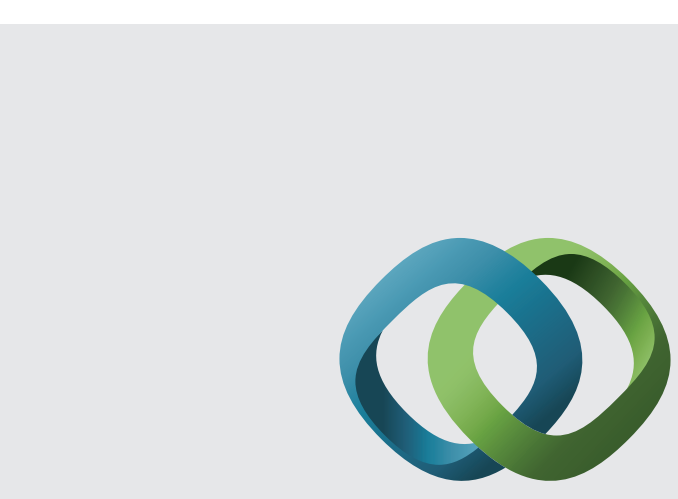

\section{Hindawi}

Submit your manuscripts at

http://www.hindawi.com
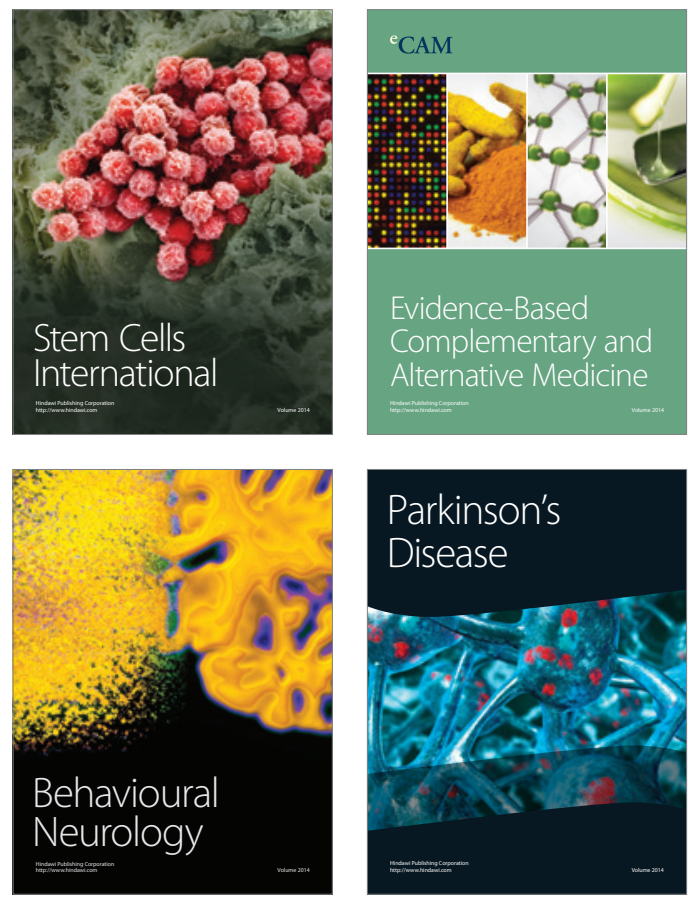
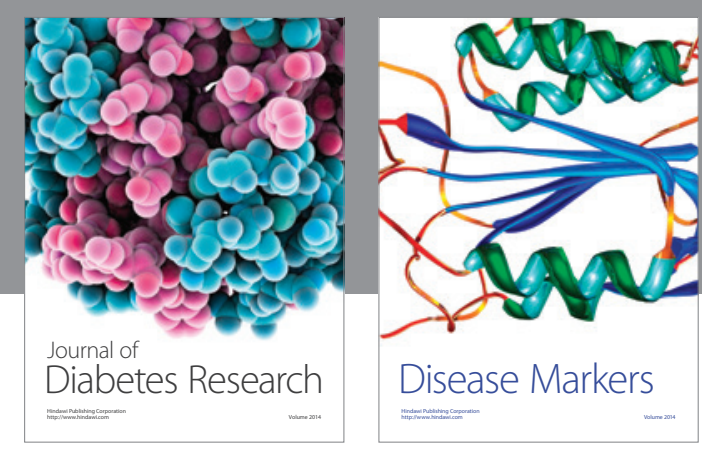

Disease Markers
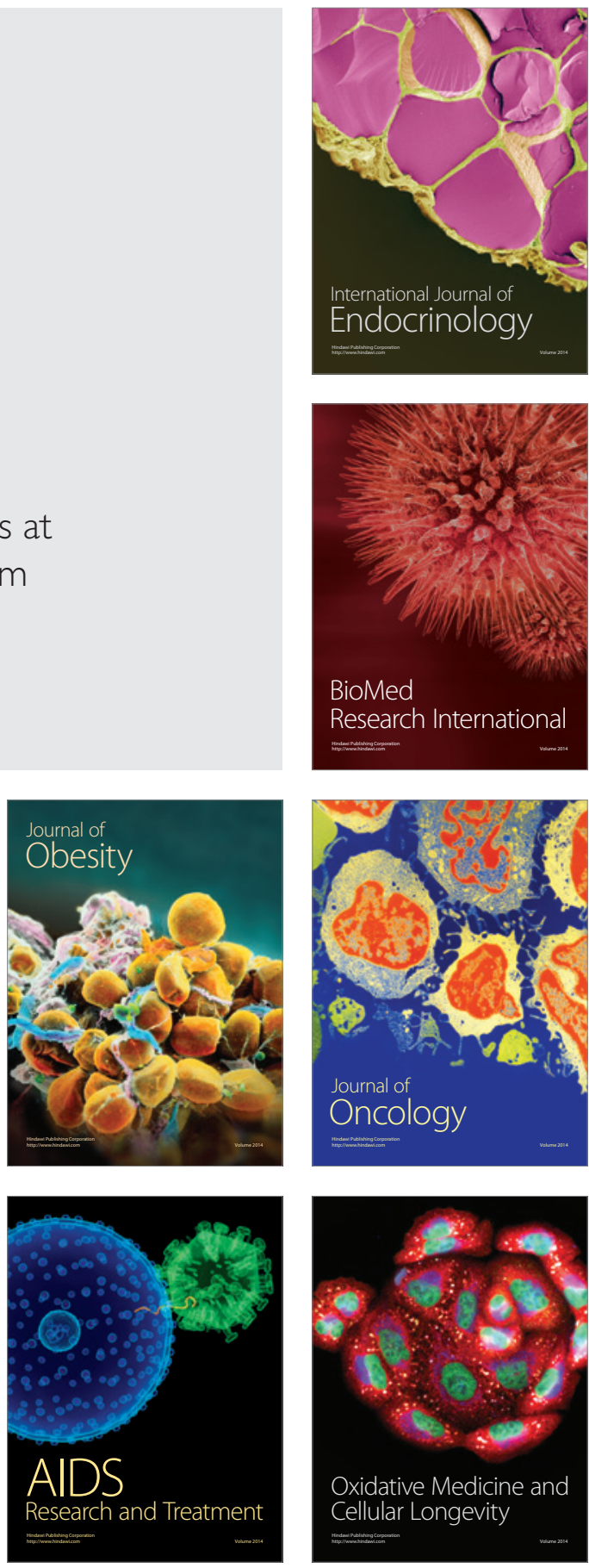